Check for updates

Cite this: RSC Adv., 2017, 7, 40673

Received 29th June 2017

Accepted 6th August 2017

DOI: 10.1039/c7ra07202c

rsc.li/rsc-advances

\title{
The fabrication of $\mathrm{CdS} / \mathrm{CoFe}_{2} \mathrm{O}_{4} / \mathrm{rGO}$ photocatalysts to improve the photocatalytic degradation performance under visible light
}

\begin{abstract}
Xinlin Liu, ${ }^{a}$ Yingying Qin, ${ }^{b}$ Yongsheng Yan (D) *b and Peng Lv ${ }^{c}$
A magnetic photocatalyst, $\mathrm{CdS} / \mathrm{CoFe}_{2} \mathrm{O}_{4} / \mathrm{rGO}$, has been successfully prepared via a simple hydrothermal method. The photocatalytic activity of the as-obtained composite photocatalyst was evaluated using the degradation of tetracycline. When compared with single $\mathrm{CdS}$ and $\mathrm{CoFe}_{2} \mathrm{O}_{4}$, the hybrid material (CdS/ $\mathrm{CoFe}_{2} \mathrm{O}_{4} / \mathrm{rGO}$ ) can enhance the photocatalytic activity. The photocurrent responses and PL spectra indicate that the composite photocatalyst can effectively separate the electron-hole pairs and restrain their recombination. This was attributed to the high charge carrier mobility of $r G O$ and the heterostructured photocatalytic system, which promotes the separation of charge carriers. In all, the $\mathrm{CdS} / \mathrm{CoFe}_{2} \mathrm{O}_{4} / \mathrm{rGO}$ photocatalyst, as a strong magnetic photocatalyst, is promising for further practical application in wastewater treatment.
\end{abstract}

\section{Introduction}

Within the background of rapid economic development, environmental governance is gradually being focused upon. Semiconductor mediated photocatalysis has attracted considerable attention because it provides highly efficient and energy saving pathway for disposing wastewater and water purification.

Cadmium sulphide (CdS) is an essential II-VI group semiconductor, which has been studied extensively due to its narrow band gap $\left(E_{\mathrm{g}}=2.42 \mathrm{eV}\right)$ at $300 \mathrm{~K}$, high absorption coefficient > $10^{4}$ and size dependent electronic and optical properties. Therefore, CdS is an attractive candidate as a photocatalyst, which can efficiently absorb visible light. ${ }^{1-4}$ However, its activity and stability far from satisfying the demand of researchers because of rapid charge recombination and photo-corrosion, which limit its large scale applications. ${ }^{5,6}$ Also, it is desirable that the photocatalyst material should be easily separable from the reaction system after the degradation of the target pollutant. There are many ways to solve the problems to enhance the photocatalytic activity of CdS, such as the deposition of noble metallic compounds, ${ }^{7,8}$ the preparation CdS quantum dots ${ }^{9,10}$ and the formation of heterojunction semiconductors. ${ }^{11,12} \mathrm{~A}$ nanocomposite heterostructured system utilizing two semiconductor materials with different band gaps is a novel strategy used to improve the photocatalytic activity. Simultaneously, considering recycling is a necessary factor for an outstanding

${ }^{a}$ School of Energy and Power Engineering, Jiangsu University, Zhenjiang 212013, China ${ }^{b}$ School of Chemistry and Chemical Engineering, Jiangsu University, Zhenjiang 212013, China.E-mail: liuxl@ujs.edu.cn

${ }^{c}$ School of Material Science \& Engineering, Jiangsu University, Zhenjiang 212013, China photocatalyst, we adopted a magnetic material to form a Type II heterojunction with CdS. Recently, spinel cobalt ferrite $\left(\mathrm{CoFe}_{2} \mathrm{O}_{4}\right)$ nanoparticles have attracted a great deal of attention due to their chemical stability, mechanical hardness, magnetocrystalline anisotropy, high coercivity and moderate saturation magnetization..$^{13,14}$ The large saturation magnetization of novel materials based on $\mathrm{CoFe}_{2} \mathrm{O}_{4}$ allows fast and effective separation from an aqueous solution using an external magnet, so $\mathrm{CoFe}_{2} \mathrm{O}_{4}$ has been widely applied in the photocatalysis field. For example, Wetchakun ${ }^{15}$ synthesized a $\mathrm{CoFe}_{2} \mathrm{O}_{4} / \mathrm{CeO}_{2}$ nanocomposite material by coupling a precipitation method with a hydrothermal method, which was used as a magnetic photocatalyst for degrading organic pollutants. Gupta ${ }^{16}$ combined $\mathrm{CoFe}_{2} \mathrm{O}_{4}$ with $\mathrm{TiO}_{2}$ using a hydrothermal method to degrade chlorpyrifos. Moreover, other composite photocatalysts have also been reported, such as $\mathrm{CoFe}_{2} \mathrm{O}_{4} /$ graphene, ${ }^{17} \mathrm{CoFe}_{2} \mathrm{O}_{4} /$ $\mathrm{ZnO},{ }^{18} \mathrm{CoFe}_{2} \mathrm{O}_{4} / \mathrm{Ag}_{3} \mathrm{PO}_{4}$ (ref. 19) and so on. Moreover, supports are always used to improve the performance of the photocatalyst. Graphene oxide (GO) or reduced-GO (rGO), a twodimensional (2D) monolayer of graphitic $\mathrm{sp}^{2}$ hybridized carbon, has been reported as effective for the transfer of photoelectrons due to its high electron mobility, large specific surface area and excellent thermal conductivity ${ }^{20-23}$ in semiconductor heterojunction materials to enhance the photocatalytic performance, such as $\mathrm{AgBr} / \mathrm{ZnO} / \mathrm{rGO},{ }^{24} \mathrm{Bi}_{2} \mathrm{~S}_{3} / \mathrm{TiO}_{2} /$ $\mathrm{rGO},{ }^{25}\left(\mathrm{C}_{16} \mathrm{H}_{33}\left(\mathrm{CH}_{3}\right)_{3} \mathrm{~N}\right)_{4} \mathrm{~W}_{10} \mathrm{O}_{32} / \mathrm{g}-\mathrm{C}_{3} \mathrm{~N}_{4} / \mathrm{rGO},{ }^{26}$ Ni@graphene$\mathrm{Cu}^{27}$ etc., so the fabrication of graphene-based photocatalysts has been deemed to be one of the most feasible strategies used to optimize the photocatalytic performance. ${ }^{28-30}$

On account of the above considerations, we now reported the $\mathrm{CdS} / \mathrm{CoFe}_{2} \mathrm{O}_{4} / \mathrm{rGO}$ photocatalyst prepared via a hydrothermal method. Tetracycline was chosen as a target pollutant to detect 
the photocatalytic performance. The results exhibited that both the heterojunction of $\mathrm{CdS} / \mathrm{CoFe}_{2} \mathrm{O}_{4}$ and $\mathrm{rGO}$ played important roles in the photocatalytic activity. This study provides a promising candidate for the efficient removal of tetracycline using an environmentally friendly and economical approach.

\section{Experimental}

\subsection{Chemicals and reagents}

Iron(III) nitrate nonahydrate $\left(\mathrm{Fe}\left(\mathrm{NO}_{3}\right)_{3} \cdot 9 \mathrm{H}_{2} \mathrm{O}, \mathrm{AR}\right)$, cobalt nitrate hexahydrate $\left(\mathrm{Co}\left(\mathrm{NO}_{3}\right)_{2} \cdot 6 \mathrm{H}_{2} \mathrm{O}, \mathrm{AR}\right)$ and sodium sulfide $\left(\mathrm{Na}_{2} \mathrm{~S}\right.$, $\mathrm{AR})$ were all purchased from Shanghai Chemical Reagent Co., Ltd. Polyvinylpyrrolidone (PVP, AR), ethanol $\left(\mathrm{C}_{2} \mathrm{H}_{5} \mathrm{OH}, 95 \%\right)$, potassium permanganate $\left(\mathrm{KMnO}_{4}, \mathrm{AR}\right)$, graphite power, sodium nitrate $\left(\mathrm{NaNO}_{3}, \mathrm{AR}\right)$, hydrochloric acid ( $\left.\mathrm{HCl}, \mathrm{AR}\right)$, sulfuric acid $\left(\mathrm{H}_{2} \mathrm{SO}_{4}, \mathrm{AR}\right)$ and ethanol $\left(\mathrm{C}_{2} \mathrm{H}_{5} \mathrm{OH}, 95 \%\right)$ were all supplied from Sinopharm Chemical Reagent Co., Ltd. Cadmium chloride hemi(pentahydrate) $\left(\mathrm{CdCl}_{2} \cdot 2.5 \mathrm{H}_{2} \mathrm{O}, 98 \%\right)$, ethylene glycol (98\%, AR), hydrogen peroxide $\left(\mathrm{H}_{2} \mathrm{O}_{2}, 30 \%\right)$, sodium hydroxide $(\mathrm{NaOH}, 97 \%)$ and L-cysteine $\left(\mathrm{C}_{3} \mathrm{H}_{7} \mathrm{NO}_{2} \mathrm{~S}, \mathrm{AR}\right)$ were all purchased from Aladdin Chemistry Co., Ltd. Tetracycline was analytically pure and used without any further purification. Distilled water was used in all our experiments.

\subsection{Synthesis}

2.2.1 Preparation of GO. Graphene oxide (GO) was synthesized using the modified Hummer's method, ${ }^{31,32}$ through the natural oxidation of graphite powder. Firstly, $1 \mathrm{~g}$ of graphite powder, $2.5 \mathrm{~g}$ of $\mathrm{NaNO}_{3}$ and $30 \mathrm{~mL}$ of concentrated $\mathrm{H}_{2} \mathrm{SO}_{4}$ were added to a $250 \mathrm{~mL}$ three-necked flask, then placed in an ice bath and stirred to obtain a homogeneous suspension. Secondly, $4 \mathrm{~g}$ of $\mathrm{KMnO}_{4}$ was added to the suspension and stirred for $2 \mathrm{~h}$ until the mixture turned green, after that the mixture was cooled down to $0{ }^{\circ} \mathrm{C}$. Subsequently, the resulting dark green suspension was removed from the ice bath and the temperature increased to $40{ }^{\circ} \mathrm{C}$ for $20 \mathrm{~min}$. Then, $30 \mathrm{~mL}$ of deionized water was added to the reaction mixture and stirred at $98{ }^{\circ} \mathrm{C}$ for $30 \mathrm{~min} .10 \mathrm{~mL}$ of $30 \% \mathrm{H}_{2} \mathrm{O}_{2}$ and $40 \mathrm{~mL}$ of deionized water were added respectively to terminate the reaction when the solution turned dark brown. The final product was collected by precipitation and centrifugation, washed with $30 \% \mathrm{HCl}$ and dried in vacuo at $60{ }^{\circ} \mathrm{C}$ for $10 \mathrm{~h}$.

2.2.2 Preparation of $\mathrm{CoFe}_{2} \mathrm{O}_{4}$. Pure $\mathrm{CoFe}_{2} \mathrm{O}_{4}$ was synthesized using a traditional hydrothermal method. Briefly, $4 \mathrm{mM}$ $\mathrm{Fe}\left(\mathrm{NO}_{3}\right)_{3} \cdot 9 \mathrm{H}_{2} \mathrm{O}$ and $2 \mathrm{mM} \mathrm{Co}\left(\mathrm{NO}_{3}\right)_{2} \cdot 6 \mathrm{H}_{2} \mathrm{O}$ were dissolved in 40 $\mathrm{mL}$ of ethylene glycol, followed by the addition of $15 \mathrm{mM}$ PVP under mechanically stirring for $30 \mathrm{~min}$ to obtain a clear solution. Then, the solution was transferred into a Teflon-lined stainless steel autoclave for hydrothermal treatment at $240{ }^{\circ} \mathrm{C}$ for $24 \mathrm{~h}$. After the autoclave was allowed to cool to room temperature naturally, the as-formed precipitate was collected by centrifugation, washed several times with water and ethanol, and dried at $60{ }^{\circ} \mathrm{C}$ for $12 \mathrm{~h}$.

2.2.3 Preparation of $\mathrm{CdS} / \mathrm{CoFe}_{2} \mathrm{O}_{4} / \mathbf{r G O}$. CdS/CoFe ${ }_{2} \mathrm{O}_{4} / \mathrm{rGO}$ was synthesized via a simple hydrothermal method. Briefly, $0.1833 \mathrm{~g}$ of $\mathrm{CdCl}_{2} \cdot 2.5 \mathrm{H}_{2} \mathrm{O}$ and $0.1756 \mathrm{~g}$ of $\mathrm{L}$-cysteine were dissolved together in $40 \mathrm{~mL}$ of deionized water and stirred for $30 \mathrm{~min}$. Then, the $\mathrm{pH}$ was adjusted to $\mathrm{pH}=7.0$ using $0.1 \mathrm{~mol} \mathrm{~L}^{-1} \mathrm{NaOH}$, then $0.05 \mathrm{~g}$ of $\mathrm{CoFe}_{2} \mathrm{O}_{4}$ and $0.05 \mathrm{~g}$ of GO were added to the above suspension and allowed to dissolve for $30 \mathrm{~min}$. Then, $0.045 \mathrm{~g}$ of $\mathrm{Na}_{2} \mathrm{~S} \cdot 9 \mathrm{H}_{2} \mathrm{O}$ was added to the above suspension and stirred for $30 \mathrm{~min}$ under a nitrogen atomsphere. Subsequently, the solution was transferred into a Teflon-lined stainless steel autoclave for hydrothermal treatment at $180{ }^{\circ} \mathrm{C}$ for $2 \mathrm{~h}$. The suspension was separated using an external magnet and the precipitate was washed with ethanol and water, and dried in vacuo at $60{ }^{\circ} \mathrm{C}$ for $24 \mathrm{~h}$. The preparation process of CdS/CoFe ${ }_{2} \mathrm{O}_{4} / \mathrm{rGO}$ is shown in Scheme 1.

\subsection{Characterization}

In this work, X-ray diffraction (XRD) patterns were obtained using a D/max-X-ray diffractometer (Rigaku, Japan), which was equipped with Ni-filtrated $\mathrm{Cu} \mathrm{K} \alpha$ radiation $(40 \mathrm{kV}, 30 \mathrm{~mA})$ to characterize the crystal structure. The $2 \theta$ scanning angle range was $10-80^{\circ}$ at a scanning rate of $5^{\circ} \mathrm{min}^{-1}$. Transmission electron microscopy (TEM) images were examined on an F20 S-

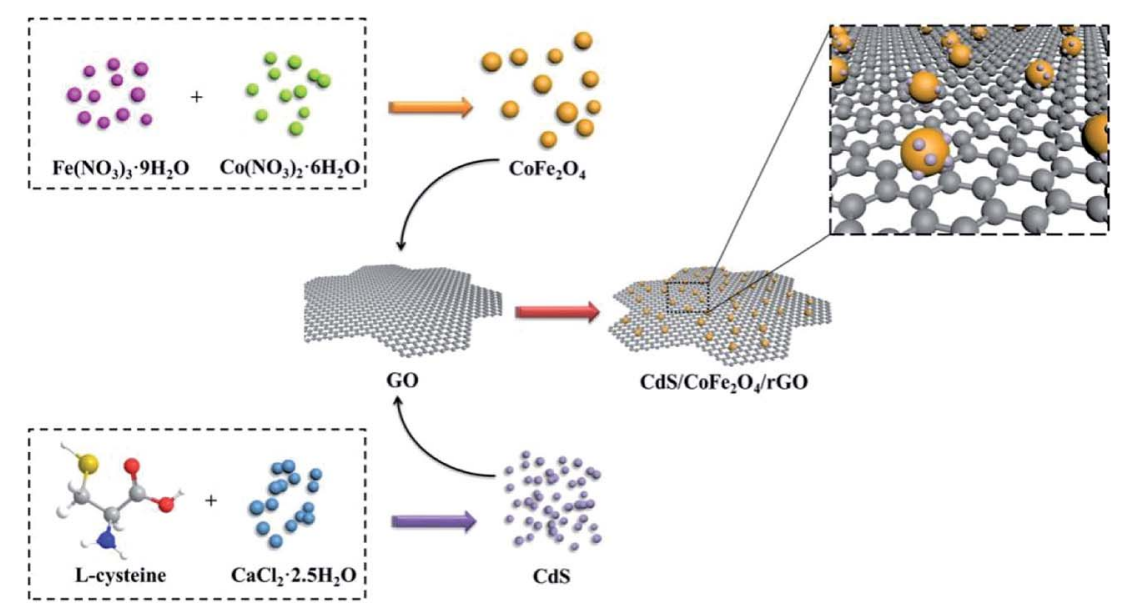

Scheme 1 A schematic illustration of the formation of $\mathrm{CdS} / \mathrm{CoFe} \mathrm{O}_{4} / \mathrm{rGO}$. 
TWIN electron microscope (Tecnai G2, FEI Co.). The SEM images were collected with S-4800 scanning electron microscopy (HITACHI, Japan). The UV-vis diffuse reflectance spectra (UV-vis DRS) of the photocatalyst power was obtained for the dry-pressed disk samples using a Specord 2450 spectrometer (Shimazu, Japan) equipped with an integrated sphere accessory for diffuse reflectance spectra using $\mathrm{BaSO}_{4}$ as the reference sample. Raman experiments were performed using a DXR spectrometer with a $532 \mathrm{~nm}$ laser and the measurements were made in a back scattering geometry. The room-temperature photoluminescence (PL) spectra of the samples were investigated utilizing a Cary Eclipse Spectrophotometer (VARIAN, USA) equipped with a xenon (Xe) lamp. The magnetic measurements were carried out using a vibrating sample magnetometer (VSM) (HH-15, Jiangsu University). The photocurrent and electrochemical impedance spectroscopy (EIS) measurements were conducted on a CHI852C electrochemical workstation and CHI760E workstation, respectively. The ESR signals of the radicals spin-trapped by the spin-trapping reagent 5,5-dimethyl1-pyrroline N-oxide (DMPO) were investigated on a Bruker EPR A 300-10/12 spectrometer.

\subsection{Activity test}

The photocatalytic activity test of the as-prepared photocatalyst was investigated by degrading tetracycline with an initial concentration of $20 \mathrm{mg} \mathrm{L}^{-1}$ under visible light irradiation (a $350 \mathrm{~W}$ Xe lamp with a $420 \mathrm{~nm}$ cut-off filter). In brief, $0.1 \mathrm{~g}$ catalyst was dispersed in $100 \mathrm{~mL}$ of tetracycline aqueous solution. Before irradiation, the photocatalyst solution was mechanically stirred for $30 \mathrm{~min}$ to establish an absorptiondesorption equilibrium between tetracycline and the photocatalyst. At given time intervals, small aliquots were sampled and centrifuged twice at $10000 \mathrm{rpm}$ for $3 \mathrm{~min}$ to remove the photocatalyst nanoparticles and analyzed by recording the variation in the absorption band (358 nm) in the UV-vis spectrum of tetracycline using a UV-vis spectrophotometer. The photocatalytic degradation rate (Dr) was calculated as follows:

$$
\eta=\left(C_{0}-C_{\mathrm{t}}\right) / C_{0}
$$

where $\eta$ is the Dr; $C_{0}$ is solution concentration at the end of the dark reaction; $C_{\mathrm{t}}$ is the absorption of the reaction solution.

\subsection{Photoelectrochemical (PEC) measurements}

The photocurrent was measured on an CHI852C electrochemical workstation using a standard three-electrode system. The IPCE measurements were carried out in a three-electrode. The CdS, CdS/CoFe $\mathrm{O}_{4}$ and $\mathrm{CdS} / \mathrm{CoFe}_{2} \mathrm{O}_{4} / \mathrm{rGO}$ samples on FTO substrates were used as working electrodes, and $\mathrm{Ag} / \mathrm{AgCl}$ (saturated $\mathrm{KCl}$ ) and platinum wire as the reference and counter electrodes, respectively. The working electrode was in the range of $1 \mathrm{~cm}^{2}$ with $0.5 \mathrm{M} \mathrm{NaSO}_{4}$ solution as a supporting electrolyte with $0.5 \mathrm{~V}$ versus SCE applied on the photoanode for the photocurrent test on the on-light conditions. EIS measurements were carried out in a three-electrode electrochemical cell on a CHI760E electrochemical workstation. A $0.1 \mathrm{M} \mathrm{KCl}$ solution containing $5 \mathrm{mM} \mathrm{Fe}(\mathrm{CN})_{6}{ }^{3-/ 4-}$ was used as the electrolyte.

\section{Results and discussion}

\subsection{XRD analysis}

The XRD patterns of the CdS (a), $\mathrm{CoFe}_{2} \mathrm{O}_{4}$ (b) and CdS/CoFe $\mathrm{O}_{4} /$ rGO (c) samples are displayed in Fig. 1. The diffraction peaks of pure CdS located at $24.8^{\circ}, 26.5^{\circ}, 28.1^{\circ}, 43.6^{\circ}, 47.7^{\circ}$ and $52.7^{\circ}$ corresponding to (1 $\left.\begin{array}{ll}1 & 0\end{array}\right),\left(\begin{array}{lll}0 & 0 & 2\end{array}\right),\left(\begin{array}{lll}1 & 0 & 1\end{array}\right),\left(\begin{array}{lll}1 & 1 & 0\end{array}\right),\left(\begin{array}{lll}1 & 0 & 3\end{array}\right)$ and $\left(\begin{array}{lll}2 & 0 & 1\end{array}\right)$ can be indexed to CdS with a greenockite structure (JCPDS No. 41-1049). Fig. $1 \mathrm{~b}$ at $2 \theta$ of $18.2^{\circ}, 30.1^{\circ}, 35.4^{\circ}, 43.0^{\circ}, 56.9^{\circ}$ and

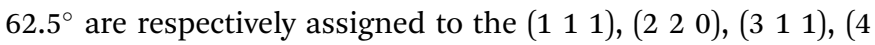
00 ), ( $\left(\begin{array}{lll}5 & 1 & 1\end{array}\right)$ and ( $\left.\begin{array}{lll}4 & 4 & 0\end{array}\right)$ diffraction planes of $\mathrm{CoFe}_{2} \mathrm{O}_{4}$ cobalt iron oxide structure (JCPDS No. 22-1086). The sharp and intense peaks illustrate that the samples are well-crystallized. Obviously, the $35.4^{\circ}, 56.9^{\circ}$ and $62.5^{\circ}$ diffraction peaks of $\mathrm{CoFe}_{2} \mathrm{O}_{4}$ in Fig. 1c become low and even disappear, which is attributed to the CdS deposition on the surface of $\mathrm{CoFe}_{2} \mathrm{O}_{4}$ and the diffraction peak of CdS is very distinct, which also reveals the successful formation of an heterojunction between CdS and $\mathrm{CoFe}_{2} \mathrm{O}_{4}$. The inset is the XRD pattern of GO, whose diffraction peak is located at $10.9^{\circ}$, but the typical diffraction peak of GO in Fig. 1c almost disappears after the hydrothermal reaction, which was attributed to the content of GO being very low.

\subsection{TEM images}

Fig. 2 shows the TEM images of the CdS nanoparticles, $\mathrm{CoFe}_{2} \mathrm{O}_{4}$, $\mathrm{GO}$ and $\mathrm{CdS} / \mathrm{CoFe}_{2} \mathrm{O}_{4} / \mathrm{rGO}$, respectively. From Fig. 2a, the CdS nanoparticles are seriously aggregated; the main aggregation may be due to the as-prepared CdS nanoparticles with the "small size effect and surface effect" have more opportunities to combine together. From Fig. 2b, $\mathrm{CoFe}_{2} \mathrm{O}_{4}$ has a uniform particle size and the size was about $20 \mathrm{~nm}$. The interplanar spacings ( $d$ values) were measured to be 0.297 and $0.254 \mathrm{~nm}$, in good

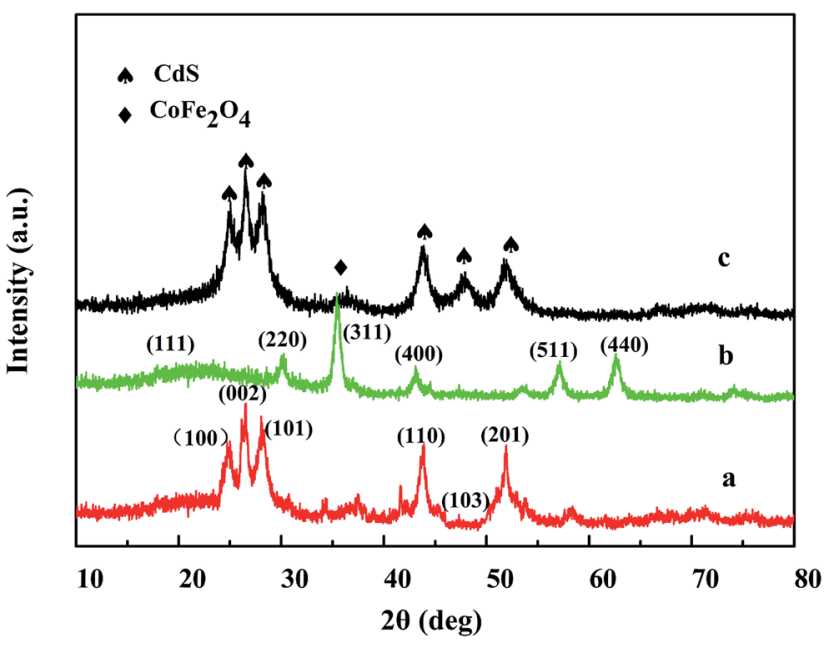

Fig. 1 The XRD patterns obtained for $\mathrm{CdS}$ (a), $\mathrm{CoFe}_{2} \mathrm{O}_{4}$ (b), CdS/ $\mathrm{COFe}_{2} \mathrm{O}_{4} / \mathrm{rGO}$ (c). 


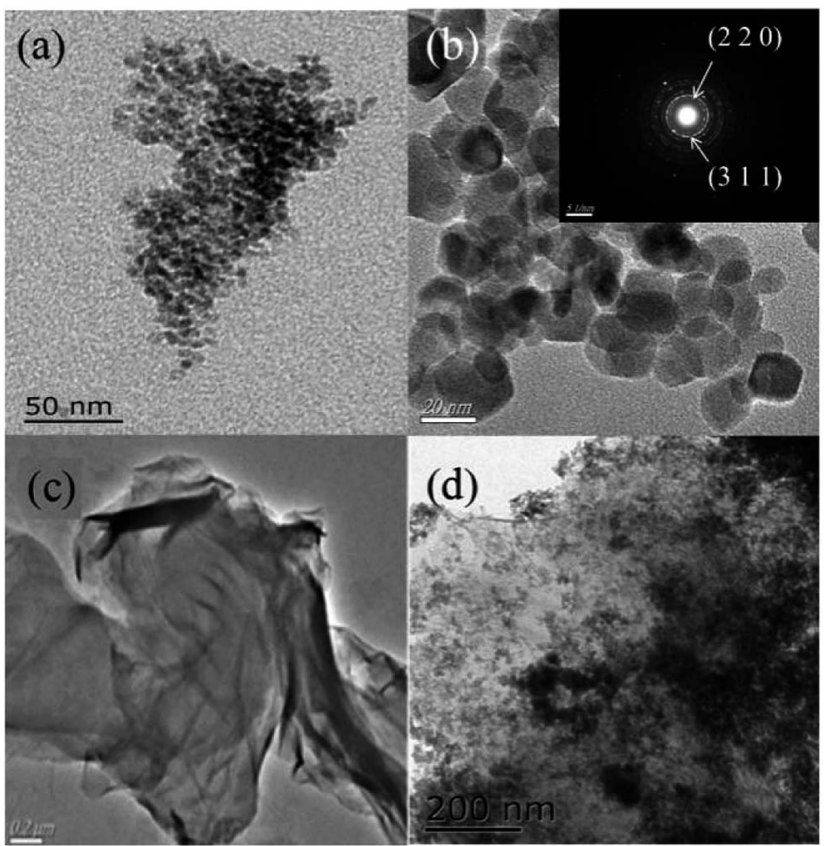

Fig. 2 TEM images of the (a) $\mathrm{CdS}$ nanoparticles, (b) $\mathrm{CoFe}_{2} \mathrm{O}_{4}$ nanoparticles; the inset is the $\mathrm{CoFe}_{2} \mathrm{O}_{4} \mathrm{SAED}$ pattern, (c) $\mathrm{GO}$ and (d) magnified $\mathrm{CdS} / \mathrm{CoFe}_{2} \mathrm{O}_{4} / \mathrm{rGO}$.

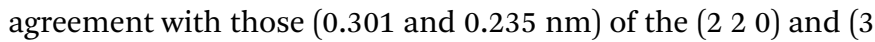
1 1) crystal planes of the standard $\mathrm{CoFe}_{2} \mathrm{O}_{4}$ sample, indicating the $\mathrm{CoFe}_{2} \mathrm{O}_{4}$ sample possessed good crystallinity. The observation of multiple bright electron diffraction rings in the SAED patterns (inset of Fig. 2b). Fig. 2c shows that rGO exhibits a typical wrinkled texture and most of the sheets resembled slightly crumpled paper. As shown in Fig. 2d, a relatively uniform distribution of the $\mathrm{CdS}$ and $\mathrm{CoFe}_{2} \mathrm{O}_{4}$ nanoparticles on the rGO sheets was obtained by the introduction rGO. This may be because an interfacial electron field was established on the interface between the $\mathrm{rGO}$ and the $\mathrm{CdS}$ and $\mathrm{CoFe}_{2} \mathrm{O}_{4}$ nanoparticles.

\subsection{SEM images}

Fig. 3a-c show the different magnification SEM images of CdS/ $\mathrm{CoFe}_{2} \mathrm{O}_{4} /$ rGO. From Fig. 3a, we can clearly see that the surface of the $\mathrm{CdS} / \mathrm{CoFe}_{2} \mathrm{O}_{4} / \mathrm{rGO}$ was very rough and the CdS nanoparticles are different in shape, the CdS was homogeneously distributed on the $\mathrm{CoFe}_{2} \mathrm{O}_{4}$ and $\mathrm{rGO}$, and the construction of the CdS and $\mathrm{CoFe}_{2} \mathrm{O}_{4}$ heterojunction. In Fig. $3 \mathrm{~b}$ is the magnified image of $\mathrm{CoFe}_{2} \mathrm{O}_{4}$ with $\mathrm{CdS}$, which exhibits spherical-like nanoparticles. We intercepted a portion from Fig. $3 \mathrm{c}$ to complete the EDX measurement. The corresponding EDX measurement further confirms the existence of the elements Co, Fe, O, Cd, S, C and Au. Quantitative analysis reveals that the atomic ratio of $\mathrm{Co}$ and $\mathrm{Fe}$ in the hybrid was nearly equal to $1: 2$, which is consistent with the stoichiometric composition of $\mathrm{CoFe}_{2} \mathrm{O}_{4}$. Note that the occurrence of the element Au was due to the metal spraying step performed before the SEM measurements.

\subsection{UV-vis DRS analysis}

Fig. 4 shows the UV-vis diffuse reflectance spectra of CdS, $\mathrm{CoFe}_{2} \mathrm{O}_{4}$ and the $\mathrm{CdS} / \mathrm{CoFe}_{2} \mathrm{O}_{4} / \mathrm{rGO}$ photocatalyst. For pure CdS, a strong absorption located at $c a .557 \mathrm{~nm}$ originating from the intrinsic band-edge absorption of the CdS nanoparticles can be seen. Pure $\mathrm{CoFe}_{2} \mathrm{O}_{4}$ has a remarkable absorption in the range of 200-800 nm, which may be due to its black color. In contrast, from the absorptions of pure $\mathrm{CdS}, \mathrm{CoFe}_{2} \mathrm{O}_{4}$ and the $\mathrm{CdS} /$ $\mathrm{CoFe}_{2} \mathrm{O}_{4} / \mathrm{rGO}$ nanocomposite, it can be seen that the absorption at all wavelengths was much stronger in the $\mathrm{CdS} / \mathrm{CoFe}_{2} \mathrm{O}_{4} / \mathrm{rGO}$ nanocomposite due to the presence of rGO and the formation of the heterojunction between $\mathrm{CdS}$ and $\mathrm{CoFe}_{2} \mathrm{O}_{4}$. This increase in the absorbance in the visible light region is in accordance with the color change of the photocatalyst from golden yellow to

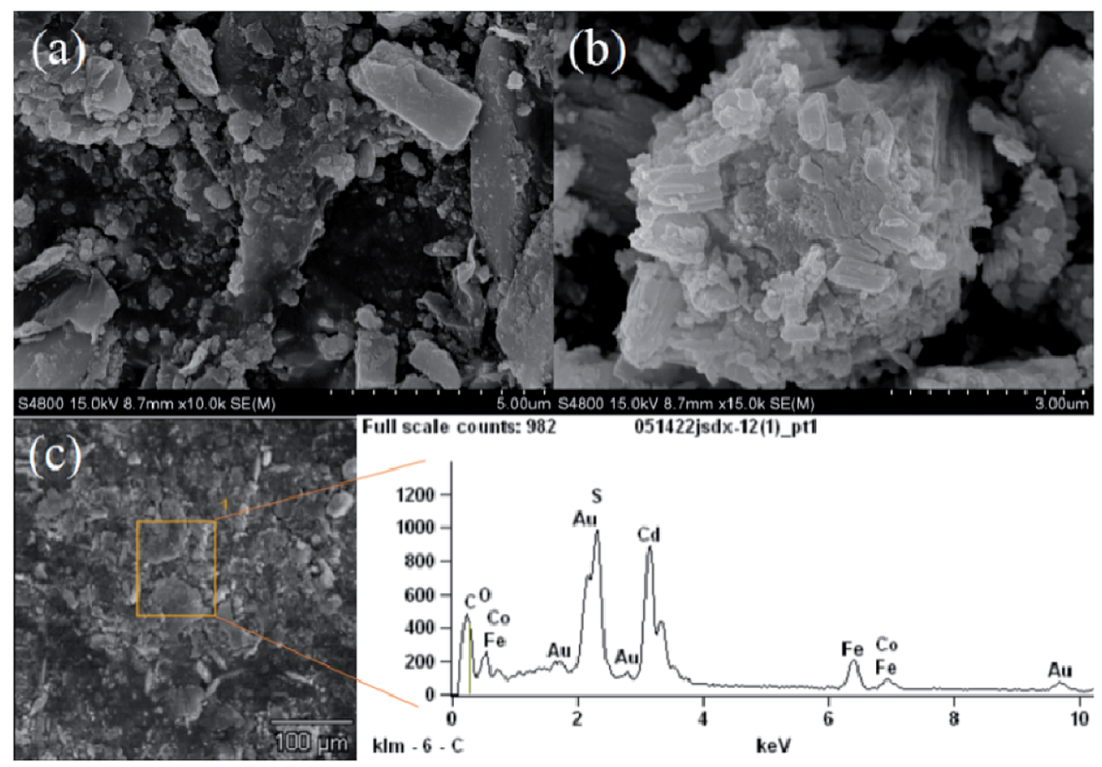

Fig. 3 The SEM images of $\mathrm{CdS} / \mathrm{CoFe}_{2} \mathrm{O}_{4} / \mathrm{rGO}$. 


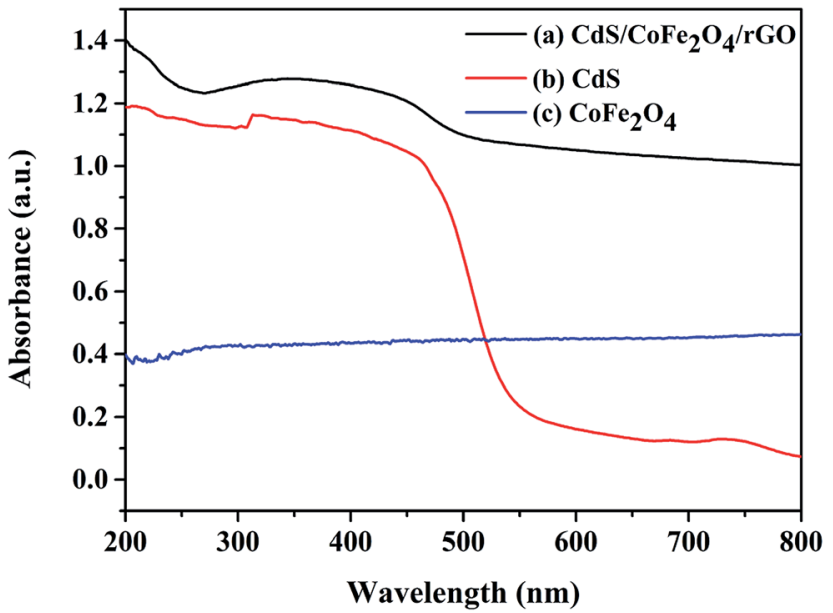

Fig. 4 The UV-vis diffuse reflectance spectra of CdS and CdS/ $\mathrm{CoFe}_{2} \mathrm{O}_{4} / \mathrm{rGO}$.

deep brown and should have implications in the photocatalytic capability of the composite..$^{33}$ The band gap of the samples can be calculated as follows:

$$
\alpha(h \nu)=A\left(h \nu-E_{\mathrm{g}}\right)^{n / 2}
$$

where $\alpha, \nu, A, E_{\mathrm{g}}$ and $n$ are the absorption coefficient, light frequency, constant, band gap energy and $n=1$ for a directband-gap semiconductor and $n=4$ for an indirect-band-gap semiconductor. ${ }^{34}$ Pristine CdS was calculated from the optical absorption $(\alpha h \nu)^{1 / 2}$ versus photon energy plot in accordance with previous studies where CdS has been considered as an direct band gap material. So from Fig. 4, the estimated bandgap values are $2.23 \mathrm{eV}$ and $1.58 \mathrm{eV}$ corresponding to pure CdS and $\mathrm{CdS} / \mathrm{CoFe}_{2} \mathrm{O}_{4} / \mathrm{rGO}$, respectively. This may be ascribed to the accessional sub-band gap energy levels induced by the serious interface and surface defects in the agglomerated nanoparticles. $^{35}$

\subsection{Raman spectra analysis}

In order to study the bonding properties and defects of graphitic materials, $\mathrm{GO}$ and $\mathrm{CdS} / \mathrm{CoFe}_{2} \mathrm{O}_{4} / \mathrm{rGO}$ were analyzed by Raman spectroscopy. The $\mathrm{sp}^{3}$ structural defects in carbon and the stretching of the $\mathrm{C}-\mathrm{C}$ bonds in the graphitic materials seen from $\mathrm{D}$ band are ascribed to the $\mathrm{G}$ band, which is the typical in-plane vibration of $\mathrm{sp}^{2}$ bonded carbons. ${ }^{36}$ Fig. 5 shows the spectra of GO and $\mathrm{CdS} / \mathrm{CoFe}_{2} \mathrm{O}_{4} / \mathrm{rGO}$. The Raman spectra shown in Fig. 5 reveals the characteristic D and G bands observed at 1343 and $1589 \mathrm{~cm}^{-1}$ found in GO, respectively. However, the G bands of the as-prepared $\mathrm{CdS} / \mathrm{CoFe}_{2} \mathrm{O}_{4} / \mathrm{rGO}$ are shifted to the lower frequency region when compared to the $\mathrm{G}$ bands of $\mathrm{GO}$ after the hydrothermal process. This phenomenon can be attributed to the recovery of the hexagonal network of carbon atoms with defects. ${ }^{37}$ The corresponding $I(\mathrm{D}) / I(\mathrm{G})$ ratio of $\mathrm{GO}$ and $\mathrm{CdS} / \mathrm{CoFe}_{2} \mathrm{O}_{4} / \mathrm{rGO}$ in Fig. 5 were calculated to be 0.945 and 1.020 , respectively. This increase may due to the high amount of defects after the reaction treatment or remnants of $\mathrm{GO}^{34}$ We barely observed the

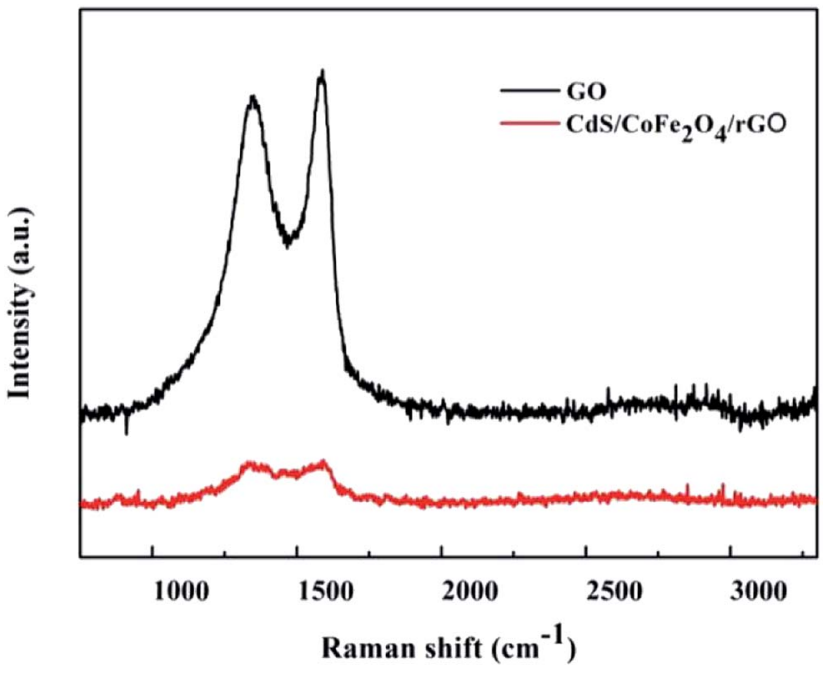

Fig. 5 The Raman spectra of $\mathrm{GO}$ and $\mathrm{CdS} / \mathrm{CoFe}_{2} \mathrm{O}_{4} / \mathrm{rGO}$.

characteristic Raman peak of CdS, which may due to the disturbing of the strong fluorescence properties in CdS. ${ }^{38}$

\subsection{Magnetic properties analysis}

The magnetic properties of the as-prepared sample was measured by VSM at room temperature. Fig. 6 shows the hysteresis loops of $\mathrm{CoFe}_{2} \mathrm{O}_{4}$ and $\mathrm{CdS} / \mathrm{CoFe}_{2} \mathrm{O}_{4} / \mathrm{rGO}$. The VSM curve of $\mathrm{CoFe}_{2} \mathrm{O}_{4}$ shows that the saturation magnetization was $43.58 \mathrm{emu} \mathrm{g}^{-1}$ at $15026.85 \mathrm{Oe}$, which was higher than the photocatalyst. The size and shape anisotropy here play critical roles in determining the magnetic properties. ${ }^{39}$ With the assembly of the CdS nanoparticles on the surface of $\mathrm{CoFe}_{2} \mathrm{O}_{4}$, the saturation magnetization $\left(M_{\mathrm{S}}\right)$ of $\mathrm{CdS} / \mathrm{CoFe}_{2} \mathrm{O}_{4} / \mathrm{rGO}$ decreased to $14.41 \mathrm{emu} \mathrm{g}^{-1}$ at 15094.50 Oe, such a decrease could be a result of the presence of the non-magnetic component. ${ }^{40}$ In addition, the remanent magnetization $\left(M_{\mathrm{r}}\right)$ of $\mathrm{CdS} / \mathrm{CoFe}_{2} \mathrm{O}_{4} / \mathrm{rGO}$ was 623.9 Oe. This result shows that $\mathrm{CdS} / \mathrm{CoFe}_{2} \mathrm{O}_{4} / \mathrm{rGO}$ displays the expectant magnetic performance and can be separated and easily recovered from the treated solutions after the liquid-phase photocatalytic degradation reaction (as shown in the photograph of Fig. 6), which can facilitate the practical running of an industrial wastewater treatment process.

\subsection{Photocurrent response analysis}

The photocurrent responses of $\mathrm{CdS}, \mathrm{CdS} / \mathrm{CoFe}_{2} \mathrm{O}_{4}$ and $\mathrm{CdS} /$ $\mathrm{CoFe}_{2} \mathrm{O}_{4} / \mathrm{rGO}$ shown in Fig. 7 were explored to investigate the electron generation and recombination behavior in the photocatalytic process. The $\mathrm{CdS} / \mathrm{CoFe}_{2} \mathrm{O}_{4}$ composites exhibited a higher photocurrent response when compared to pure CdS, indicating that the synergistic effect between $\mathrm{CdS}$ and $\mathrm{CoFe}_{2} \mathrm{O}_{4}$ does indeed exist, so the separation of the photogenerated electrons and holes was increased. Obviously, the introduction of rGO forming the photocatalyst gave rise to the maximum photocurrent density in which the $\mathrm{CdS} / \mathrm{CoFe}_{2} \mathrm{O}_{4} / \mathrm{rGO}$ was higher than that of pure $\mathrm{CoFe}_{2} \mathrm{O}_{4}$ and $\mathrm{CdS} / \mathrm{CoFe}_{2} \mathrm{O}_{4}$ during the "on-off" irradiation cycles, resulting in the enhanced photocatalytic activity. 


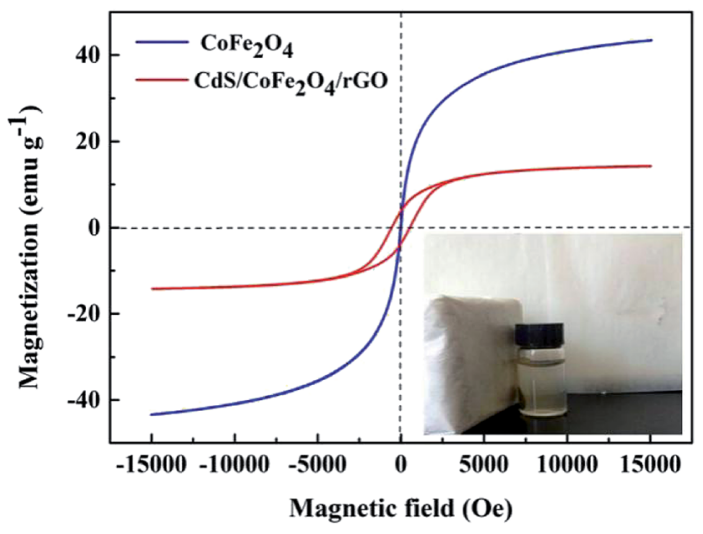

Fig. 6 The hysteresis loops of $\mathrm{CoFe}_{2} \mathrm{O}_{4}$ and $\mathrm{CdS} / \mathrm{CoFe}_{2} \mathrm{O}_{4} / \mathrm{rGO}$ under a magnetic field. Inset: a photograph showing the magnetic recycling of the $\mathrm{CdS} / \mathrm{CoFe}_{2} \mathrm{O}_{4} / \mathrm{rGO}$ photocatalyst.

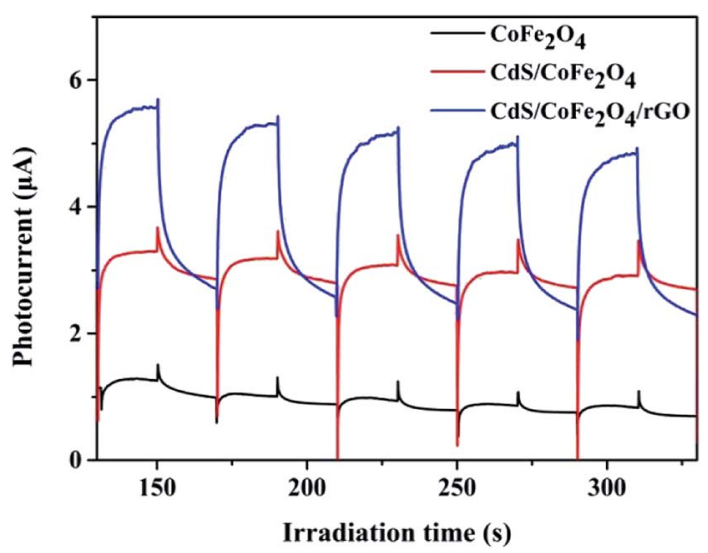

Fig. 7 The photocurrent-response of $\mathrm{CoFe}_{2} \mathrm{O}_{4}, \mathrm{CdS} / \mathrm{CoFe}_{2} \mathrm{O}_{4}$ and $\mathrm{CdS} / \mathrm{CoFe} \mathrm{O}_{4} / \mathrm{rGO}$ in a $0.5 \mathrm{M} \mathrm{Na}_{2} \mathrm{SO}_{4}$ aqueous solution under visible light irradiation.

\subsection{EIS analysis}

Electrochemical impedance spectroscopy (EIS) analysis has also been used to examine the state of the charge carriers. As shown in Fig. 8, the diameter of the Nyquist plot obtained for CdS/ $\mathrm{CoFe}_{2} \mathrm{O}_{4} / \mathrm{rGO}$ was the smallest at a high frequency. As is known to all, the high frequencies in the EIS spectra correspond to the charge transfer restrained at the contact interface both at the electrode and the electrolyte solution, and the charge transfer resistance can be directly observed by the semicircle radius. The smaller the semi arc in the EIS Nyquist plot denotes the lower recombination of the electron-hole pairs. ${ }^{41,42}$

\subsection{PL analysis}

In order to examine the charge mobility, we adopted and analyzed the transient fluorescence (FL) of CdS and CdS/ $\mathrm{CoFe}_{2} \mathrm{O}_{4} / \mathrm{rGO}$ excited at $337 \mathrm{~nm}$ (shown in Fig. 9B). The corresponding radiative lifetimes of the fitting decay curves obtained for $\mathrm{CdS}$ and $\mathrm{CdS} / \mathrm{CoFe}_{2} \mathrm{O}_{4} / \mathrm{rGO}$ are 3.62 and $1.43 \mathrm{~ns}$, respectively. The relatively shorter decay lifetime of the excited states reveals

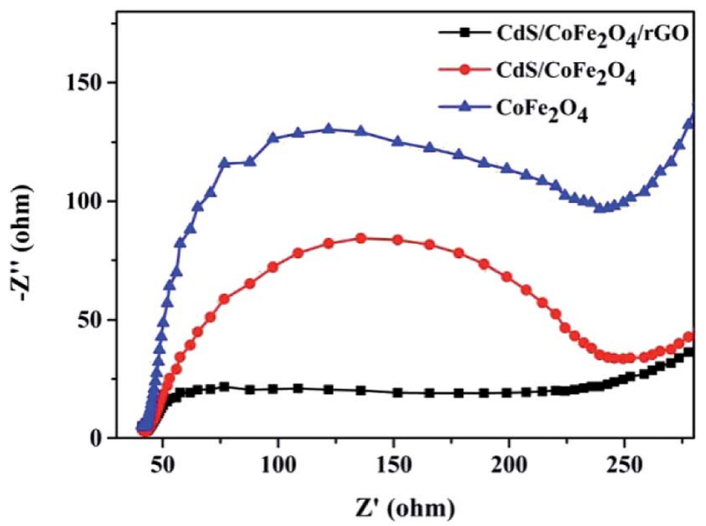

Fig. 8 Electrochemical impedance spectroscopy of the $\mathrm{CoFe}_{2} \mathrm{O}_{4}$, $\mathrm{CdS} / \mathrm{CoFe}_{2} \mathrm{O}_{4}$ and $\mathrm{CdS} / \mathrm{CoFe}_{2} \mathrm{O}_{4} / \mathrm{rGO}$ samples.

the faster interfacial electron transfer taking place in the semiconductors or the interfacial attachments and the improved separation of the electron-hole pairs. ${ }^{43}$ The quenched photoluminescence and the reduced decay lifetime further illuminate the greater separation of the photo-generated electrons and holes occurring at the interfaces of the compounds. $\mathrm{CdS} / \mathrm{CoFe}_{2} \mathrm{O}_{4} / \mathrm{rGO}$ with the shorter decay time has an excellent capacity to utilize the charge carriers.

\subsection{Photocatalytic activity}

The photocatalytic activities of the as-prepared photocatalysts were evaluated by the degradation of $20 \mathrm{mg} \mathrm{L}^{-1}$ tetracycline under visible light irradiation. In order to discuss the effect different proportion of $\mathrm{CoFe}_{2} \mathrm{O}_{4}$ on the photocatalytic activity, from the degradation dynamics curves obtained for tetracycline over the $\mathrm{CdS} / \mathrm{CoFe}_{2} \mathrm{O}_{4} / \mathrm{rGO}$ samples with different contents of $\mathrm{CoFe}_{2} \mathrm{O}_{4}$ shown in Fig. 10A, $0.05 \mathrm{~g}$ of $\mathrm{CoFe}_{2} \mathrm{O}_{4}$ in $\mathrm{CdS} / \mathrm{CoFe}_{2} \mathrm{O}_{4} /$ rGO exhibits the highest photocatalytic activity. The introduction of $\mathrm{CoFe}_{2} \mathrm{O}_{4}$ has a vital effect on the photocatalytic activity of the catalysts, which may be due to a majority of the electrons generated in the CdS can be transferred to the $\mathrm{CoFe}_{2} \mathrm{O}_{4}$ by the loaded sites under visible light irradiation; this additional route for electron transport can decrease the recombination of the electron-hole pairs. Moreover, Fig. 10B displays the photocatalytic capability of CdS, $\mathrm{CoFe}_{2} \mathrm{O}_{4}$, GO and CdS/CoFe ${ }_{2} \mathrm{O}_{4} / \mathrm{rGO}$ via the photodegradation of tetracycline. $\mathrm{CdS} / \mathrm{CoFe}_{2} \mathrm{O}_{4} / \mathrm{rGO}$ reveals the best degradation rate of $56.3 \%$, which indicates that $\mathrm{CdS} / \mathrm{CoFe}_{2} \mathrm{O}_{4} / \mathrm{rGO}$ possesses the highest photocatalytic activity when compared to the other catalysts studied.

\subsection{Stability}

The stability of a photocatalyst is a necessary condition in practical application. To investigate the stability of the photocatalyst, recycling experiments for the photo-degradation of tetracycline were carried out and the results are shown in Fig. 11. It is clearly seen that $\mathrm{CdS} / \mathrm{CoFe}_{2} \mathrm{O}_{4} / \mathrm{rGO}$ still maintains a high level of activity and does not exhibit an obviously decline after four cycles. CdS/CoFe ${ }_{2} \mathrm{O}_{4} / \mathrm{rGO}$ has satisfactory reusability during the photocatalytic reaction. 

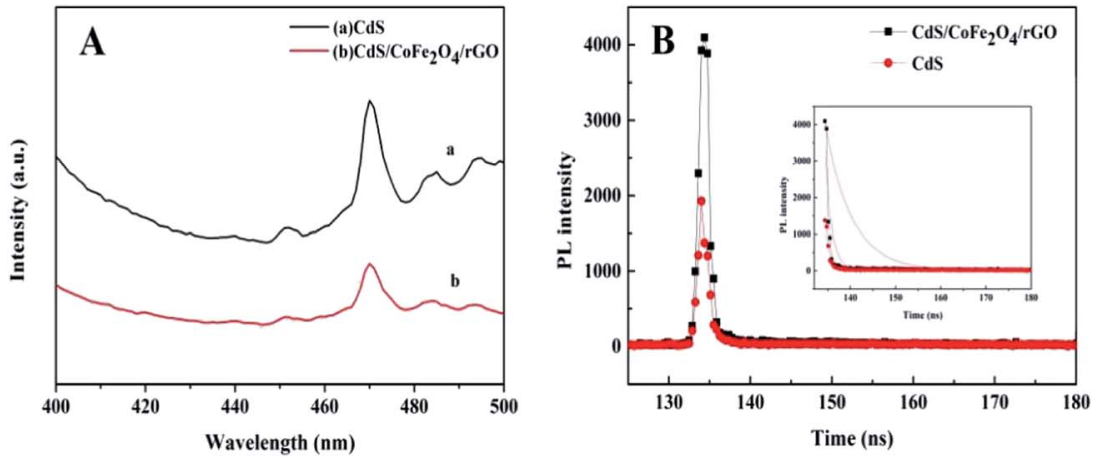

Fig. 9 The solid PL emission spectra (A) and FL emission decay (B) of $\mathrm{CdS}$ and $\mathrm{CdS} / \mathrm{CoFe}_{2} \mathrm{O}_{4} / \mathrm{rGO}$
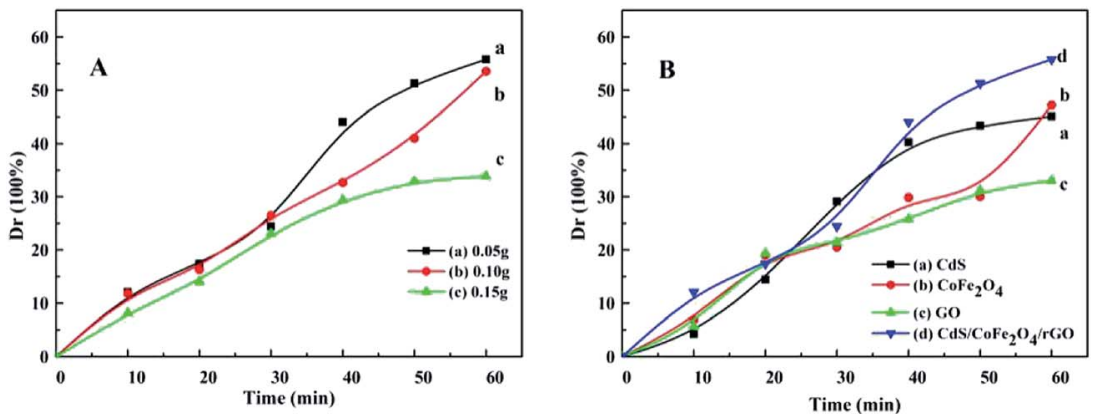

Fig. 10 The degradation dynamics curves obtained for tetracycline with the different photocatalyst samples under visible light irradiation (A and B): (A) $\mathrm{CdS} / \mathrm{CoFe}_{2} \mathrm{O}_{4} / \mathrm{rGO}$ with different $\mathrm{CoFe}_{2} \mathrm{O}_{4}$ content, (a) $0.05 \mathrm{~g}$, (b) $0.10 \mathrm{~g}$ and (c) $0.15 \mathrm{~g}$. (B) The degradation rate of the different targets (a) $\mathrm{CdS}$, (b) $\mathrm{CoFe}_{2} \mathrm{O}_{4}$, (c) $\mathrm{GO}$ and (d) $\mathrm{CdS} / \mathrm{CoFe}_{2} \mathrm{O}_{4} / \mathrm{rGO}$.

\subsection{The mechanism of the pollutant photo-degradation} process

The main active species during the photocatalysis process were determined using an electron spin resonance (ESR) spin-trap technique with DMPO, as shown in Fig. 12. Under visible light irradiation, the DMPO- ${ }^{-} \mathrm{O}_{2}{ }^{-}$adduct over $\mathrm{CdS} / \mathrm{CoFe}_{2} \mathrm{O}_{4} /$ rGO was detected in a methanol dispersion (Fig. 12A). Six

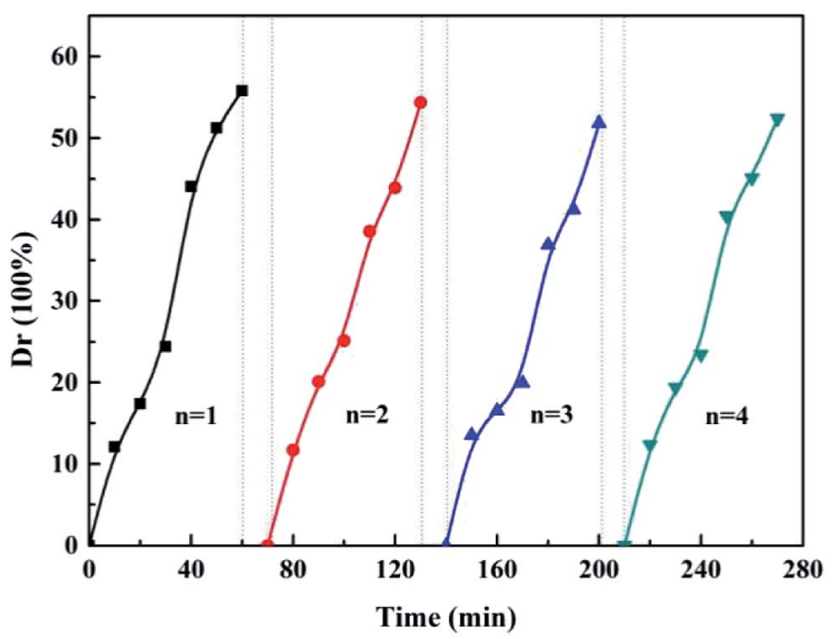

Fig. 11 The repeated the photocatalytic degradation of tetracycline experiments using the as-prepared $\mathrm{CdS} / \mathrm{CoFe}_{2} \mathrm{O}_{4} / \mathrm{rGO}$. characteristic peaks existed in the spectra, which indicated that the photogenerated electrons in the conduction band of photocatalyst can combine with $\mathrm{O} 2$ to produce ${ }^{\cdot} \mathrm{O}_{2}{ }^{-}$radicals in the process of the photo-degradation reaction. For the DMPO- ${ }^{\circ} \mathrm{OH}$ signal, there are no or a little characteristic peaks in the spectra, suggesting nearly no ${ }^{\circ} \mathrm{OH}$ was produced in the photocatalytic degradation reaction.

\subsection{The proposed mechanisms of the $\mathrm{CdS} / \mathrm{CoFe}_{2} \mathrm{O}_{4} / \mathrm{rGO}$ photocatalyst}

For the purpose of gaining insight on how to improve the photocatalytic activity of the ternary $\mathrm{CdS} / \mathrm{CoFe}_{2} \mathrm{O}_{4} / \mathrm{rGO}$ nanocomposites, the relative band edge of the $\mathrm{CdS}$ and $\mathrm{CoFe}_{2} \mathrm{O}_{4}$ semiconductors at the point of zero charge were calculated using the following empirical equations: ${ }^{44}$

$$
\begin{gathered}
E_{\mathrm{CB}}=X-E^{\mathrm{e}}-0.5 E_{\mathrm{g}} \\
E_{\mathrm{VB}}=E_{\mathrm{CB}}+E_{\mathrm{g}}
\end{gathered}
$$

where $E_{\mathrm{CB}}$ and $E_{\mathrm{VB}}$ are the conduction band (CB) and the valence band $(\mathrm{VB})$ potentials, $E^{\mathrm{e}}$ is the energy of the free electrons on the hydrogen scale $(4.5 \mathrm{eV}), X$ is electronegativity of the semiconductor (the geometric mean of the electronegativity of the constituent atom) and $E_{\mathrm{g}}$ is the band gap energy of the semiconductor. Accordingly, the $E_{\mathrm{VB}}$ of $\mathrm{CdS}$ and $\mathrm{CoFe}_{2} \mathrm{O}_{4}$ were 

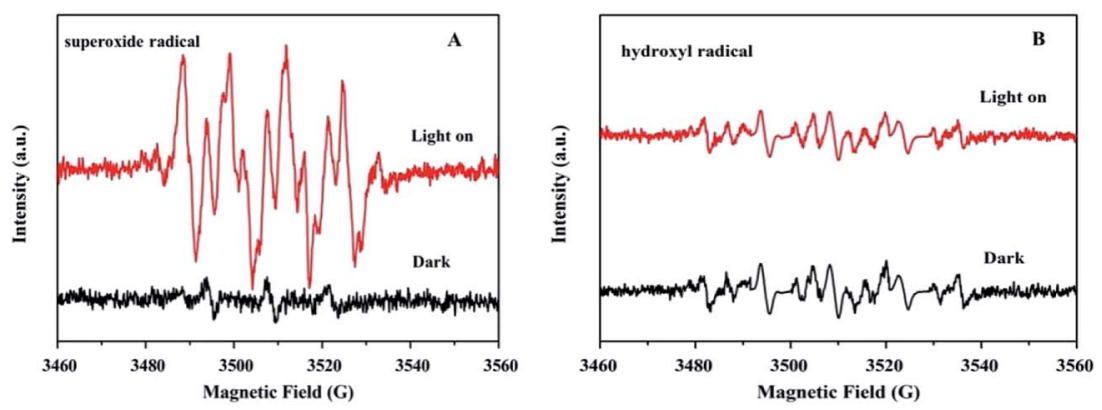

Fig. 12 The DMPO spin-trapping ESR spectra recorded with the $\mathrm{CdS} / \mathrm{CoFe}_{2} \mathrm{O}_{4} / \mathrm{rGO}$ photocatalyst in (A) a methanol dispersion (for DMPOsuperoxide radicals) and (B) an aqueous dispersion (for DMPO-hydroxyl radicals) under visible light irradiation.

calculated to be 1.88 and $1.98 \mathrm{eV}$, respectively. Similarly, the $E_{\mathrm{CB}}$ of $\mathrm{CdS}$ and $\mathrm{CoFe}_{2} \mathrm{O}_{4}$ were calculated to be -0.52 and $0.65 \mathrm{eV}$, respectively.

$$
\begin{gathered}
\mathrm{CdS}+h \nu \rightarrow \mathrm{CdS}\left(\mathrm{h}^{+}+\mathrm{e}^{-}\right) \\
\mathrm{CoFe}_{2} \mathrm{O}_{4}+h \nu \rightarrow \mathrm{CoFe}_{2} \mathrm{O}_{4}\left(\mathrm{~h}^{+}+\mathrm{e}^{-}\right) \\
\mathrm{CdS}\left(\mathrm{e}^{-}\right)+\mathrm{CoFe}_{2} \mathrm{O}_{4} \rightarrow \mathrm{CdS}+\mathrm{CoFe}_{2} \mathrm{O}_{4}\left(\mathrm{e}^{-}\right) \\
\mathrm{CoFe}_{2} \mathrm{O}_{4}\left(\mathrm{~h}^{+}\right)+\mathrm{CdS} \rightarrow \mathrm{CoFe}_{2} \mathrm{O}_{4}+\mathrm{CdS}\left(\mathrm{h}^{+}\right) \\
\mathrm{e}^{-}+\text {graphene } \rightarrow \text { graphene }\left(\mathrm{e}^{-}\right) \\
\mathrm{O}_{2}+\mathrm{e}^{-}\left(\mathrm{CoFe}_{2} \mathrm{O}_{4} \text { and graphene }\right) \rightarrow \mathrm{O}_{2}^{-} \\
\mathrm{O}_{2}^{-}+\mathrm{TC} \rightarrow \mathrm{CO}_{2}+\mathrm{H}_{2} \mathrm{O}+\text { mineral } \\
\mathrm{h}^{+}+\mathrm{TC} \rightarrow \mathrm{CO}_{2}+\mathrm{H}_{2} \mathrm{O}+\text { mineral }
\end{gathered}
$$

Upon irradiation with visible light, the $\mathrm{CdS}$ and $\mathrm{CoFe}_{2} \mathrm{O}_{4}$ nanoparticles undergo charge separation to yield electrons $\left(\mathrm{e}^{-}\right)$ and holes $\left(\mathrm{h}^{+}\right)$(reactions (5) and (6)). Because the graphene sheets are well known as good acceptors, ${ }^{45}$ the $\mathrm{e}^{-}$are quickly transferred to the sheets via a percolation mechanism (reaction (9)). Then, the negatively charged $\mathrm{e}^{-}$can react with the dissolved oxygen to produce superoxide anion radicals (reaction (10)) when the $\mathrm{e}^{-}$are transferred from the $E_{\mathrm{CB}}$ of CdS to the $E_{\mathrm{CB}}$ of $\mathrm{CoFe}_{2} \mathrm{O}_{4}$ (reaction (7)) and partial e $\mathrm{e}^{-}$of $\mathrm{CoFe}_{2} \mathrm{O}_{4}$. Then, the $\mathrm{O}_{2}{ }^{-}$can mineralize TC to generate $\mathrm{CO}_{2}, \mathrm{H}_{2} \mathrm{O}$ and mineral (reaction (11)). Furthermore, the $\mathrm{h}^{+}$of $\mathrm{CoFe}_{2} \mathrm{O}_{4}$ can transfer to $\mathrm{CdS}$ and the $\mathrm{h}^{+}$can oxidize the pollutant.

\section{Conclusions}

In summary, a novel magnetically separable $\mathrm{CdS} / \mathrm{CoFe}_{2} \mathrm{O}_{4} / \mathrm{rGO}$ photocatalyst was successfully prepared using a facile hydrothermal method. The photocatalytic experiments indicate that $\mathrm{CdS} / \mathrm{CoFe}_{2} \mathrm{O}_{4} / \mathrm{rGO}$ is a highly active photocatalyst for the degradation TC under the visible light irradiation. Furthermore, the magnetic properties of $\mathrm{CdS} / \mathrm{CoFe}_{2} \mathrm{O}_{4} / \mathrm{rGO}$ promote their easy and fast separation from an aqueous solution using an external magnetic field and the $\mathrm{CdS} / \mathrm{CoFe}_{2} \mathrm{O}_{4} / \mathrm{rGO}$ could be reused for 4 cycles without any obvious loss in its reactivity under visible light irradiation.

\section{Conflicts of interest}

There are no conflicts to declare.

\section{Acknowledgements}

We gratefully acknowledge the financial support of the Natural Science Foundation of Jiangsu Province (BK20150484), the China Postdoctoral Science Foundation (2015M570416) and the financial support of the financial support of the Research Foundation of Jiangsu University, China (14JDG148).

\section{References}

1 X. J. Liu, L. K. Pan, T. Lv, G. Zhu, Z. Sun and C. Q. Sun, Chem. Commun., 2011, 47, 11984.

2 M. Matsumura, S. Furukawa, Y. Saho and H. Tsubomura, J. Phys. Chem., 1985, 89, 1327.

3 P. Kumar, P. Singh and B. Bhattacharya, Ionics, 2011, 17, 721. 4 K. F. Wu, Z. Y. Chen, H. J. Lv, H. M. Zhu, C. L. Hill and T. Q. Lian, J. Am. Chem. Soc., 2014, 136, 7708.

5 J. Z. Chen, X. J. Wu, L. S. Yin, B. Li, X. Hong, Z. X. Fan, B. Chen, C. Xue and H. Zhang, Angew. Chem., Int. Ed., 2015, 54, 1210.

6 A. Kudo and Y. Miseki, Chem. Soc. Rev., 2009, 38, 253.

7 W. T. Chen, T. T. Yang and Y. J. Hsu, Chem. Mater., 2008, 20, 7204.

8 H. J. Yan, J. H. Yang, G. J. Ma, G. P. Wu, X. Zong, Z. B. Lei, J. Y. Shi and C. Li, J. Catal., 2009, 266, 165.

9 M. H. Entezari and N. Ghows, Ultrason. Sonochem., 2011, 18, 127.

10 A. J. Hoffman, G. Mills, H. Yee and M. R. Hoffmann, J. Phys. Chem., 1992, 96, 5546.

11 Z. Xie, X. X. Liu, W. P. Wang, X. J. Wang, C. Liu, Q. Xie, Z. C. Li and Z. J. Zhang, Nano Energy, 2015, 11, 400.

12 C. Han, Z. Chen, N. Zhang, J. C. Colmenares and Y. J. Xu, Adv. Funct. Mater., 2015, 25, 221.

13 H. Zheng, J. Wang, S. E. Lofland, Z. Ma, L. MohaddesArdabili, T. Zhao, L. Salamanca-Riba, S. R. Shinde, S. B. Ogale, F. Bai, D. Viehland, Y. Jia, D. G. Schlom, 
M. Wuttig, A. Roytburd and R. Ramesh, Science, 2004, 303, 661.

14 K. K. Senapati, C. Borgohain and P. Phukan, Catal. Sci. Technol., 2012, 2, 2361.

15 N. Wetchakun, S. Chaiwichain, K. Wetchakun, W. Kangwansupamonkon, B. Inceesungvorn and S. Phanichphant, Mater. Lett., 2013, 113, 76.

16 V. K. Gupta, T. Eren, N. Atar, M. L. Yola, C. Parlak and H. Karimi-Maleh, J. Mol. Liq., 2015, 208, 122.

17 L. Gan, S. M. Shang, C. W. M. Yuen, S. X. Jiang and E. L. Hu, Appl. Surf. Sci., 2015, 351, 140.

18 C. Borgohain, K. K. Senapati, K. C. Sarma and P. Phukan, J. Mol. Catal. A: Chem., 2012, 363-364, 495.

19 L. Gan, L. J. Xu and K. Qian, Mater. Des., 2016, 109, 354.

20 J. J. Ding, L. Z. Liu, J. J. Xue, Z. W. Zhou, G. Y. He and H. Q. Chen, J. Alloys Compd., 2016, 688, 649.

21 W. W. Zhong, A. J. Xu, R. Q. Guo and W. J. Wang, J. Alloys Compd., 2017, 696, 246.

22 Y. M. Li, X. J. Lv, J. Lu and J. H. Li, J. Phys. Chem. C, 2010, 114, 21770.

23 J. W. Zhu, G. Y. Zeng, F. D. Nie, X. M. Xu, S. Chen, Q. F. Han and X. Wang, Nanoscale, 2010, 2, 988.

24 H. H. Wang, D. L. Peng, T. Chen, Y. Chang and S. J. Dong, Ceram. Int., 2016, 42, 4406.

25 Y. Liu, Y. D. Shi, X. Liu and H. X. Li, Appl. Surf. Sci., 2017, 396, 58.

26 X. L. Yang, F. F. Qian, Y. Wang, M. L. Li, J. R. Lu, Y. M. Li and M. T. Bao, Appl. Catal., B, 2017, 200, 283.

27 L. Z. Liu, J. J. Xue, X. Y. Shan, G. Y. He, X. Wang and H. Q. Chen, Catal. Commun., 2016, 75, 13.

28 M. Khan, M. N. Tahir, S. F. Adil, H. U. Khan, M. R. Siddiqui, A. A. Al-warthan and W. Tremel, J. Mater. Chem. A, 2015, 37, 18753.

29 D. Chen, H. Zhang, Y. Liu and J. H. Li, Energy Environ. Sci., 2013, 6, 1362.
30 T. Y. Liu, B. Liu, L. F. Yang, X. L. Ma, H. Li, S. Yin, T. Sato, T. Sekion and Y. H. Wang, Appl. Catal., B, 2017, 204, 593.

31 W. S. Hummers and R. E. Offeman, J. Am. Chem. Soc., 1958, 80, 1339.

32 Y. H. Zhang, Z. R. Tang, X. Fu and Y. J. Xu, ACS Nano, 2010, 4, 7303.

33 R. Jiang, H. Y. Zhu, J. B. Li, F. Q. Fu, J. Yao, S. T. Jiang and G. M. Zeng, Appl. Surf. Sci., 2016, 364, 604.

34 G. K. Zhang, M. Li, S. J. Yu, S. M. Zhang, B. B. Huang and J. G. Yu, J. Colloid Interface Sci., 2010, 345, 467.

35 N. Kislov, S. S. Srinivasan, Y. Emirov and E. K. Stefanakos, Mater. Sci. Eng., B, 2008, 153, 70.

36 M. S. Dresselhaus, A. Jorio, M. Hofmann, G. Dresselhaus and R. Saito, Nano Lett., 2010, 10, 751.

37 L. M. P. Martinez, S. M. Torres, V. Likodimos, P. Falaras, J. L. Figueiredo, J. L. Faria and A. M. T. Sliva, Appl. Catal., $B$, 2014, 158-159, 329.

38 M. J. Zhou, D. L. Han, X. L. Liu, C. C. Ma, H. Q. Wang, Y. F. Tang, P. W. Huo, W. D. Shi, Y. S. Yan and J. H. Yang, Appl. Catal., B, 2015, 172-173, 174.

39 Q. Song and Z. J. Zhang, J. Am. Chem. Soc., 2004, 126, 6164. 40 S. Farhadi and F. Siadatnasab, Chin. J. Catal., 2016, 37, 1487. 41 L. Wu, J. Li, S. Zhang, L. Long, X. Li and C. Cen, J. Phys. Chem. C, 2013, 117, 22591.

42 W. Zhou, W. Li, J. Q. Wang, Y. Qu, Y. Yang, Y. Xie, K. Zhang, L. Wang, H. Fu and D. Zhao, J. Am. Chem. Soc., 2014, 136, 9280.

43 Y. W. Zhu, S. Murali, W. W. Cai, X. S. Li, J. W. Suk, J. R. Potts and R. S. Ruoff, Adv. Mater., 2010, 22, 3906.

44 K. F. Zhang, Y. X. Liu, J. G. Deng, S. H. Xie, H. X. Lin, X. T. Zhao, J. Yang, Z. Han and H. X. Dai, Appl. Catal., B, 2017, 202, 569.

45 I. V. Lightcap, T. H. Kosel and P. V. Kamat, Nano Lett., 2010, 10, 577 . 